\title{
IDENTITY, BELONGING AND HUMAN RIGHTS: CULTURAL CUES IN INTEGRATION PROCESSES. AN INTRODUCTION
}

\author{
DOLORES MORONDO TARAMUNDI ${ }^{1}$
}

This special issue gathers and presents to a wider audience the final results of the research line "Identity and Cultural Integration" developed within the international project INTEGRIM (Integration and international migration: pathways and integration policies). ${ }^{2}$

Migrants' integration is a long-standing topic of interest, and even concern, both for academia and policy-making. Integration has traditionally been considered mainly from an economic and labour market perspective. However, other points of view have raised claims of their own relevance and usefulness for explaining integration processes as well as for contesting notions of integration and their related policies. Among these, the perspectives that look at integration from the point of view of (human) rights entitlements and enjoyment, antidiscrimination protection or access to social and political participation have acquired growing momentum. The INTEGRIM research group gathered here partakes of these human rights based analyses of integration processes, contributing moreover a variety of disciplines (law, political science, sociology, anthropology) and methodologies (process tracing, legal discourse analysis, case study, participant observation, ethnography, situational analysis, interpretative interviewing) which enrich the understanding of the deep implications of human rights for migration and integration processes.

The main interest of the INTEGRIM research group represented here lies with the identity and cultural dimensions of integration processes. These dimensions must be considered within the increasing level of cultural, linguistic, ethnic and religious diversity of European societies, with due regard to globalised trends and the rapid and self-reflective character of cultural transformations. These dimensions pose therefore important social and political challenges both on states and private actors in respect to integration processes. As argued in the first essay of this special issue by Eduardo Ruiz Vieytez, the coordinator of the INTEGRIM network, "[t]he relevance of this dimension is that the cultural elements that shape collective identities determine the ownership and

\footnotetext{
${ }^{1}$ Human Rights Institute. University of Deusto, Bilbao (dolores.morondo@deusto.es).

${ }^{2}$ INTEGRIM is a joint research and training programme of the Seventh Framework Programme running from 2013 to 2017 (www.integrim.eu). The research leading to the results presented in this special issue has received funding from the European Union's Seventh Framework Programme (FP7/2007-2013) under grant agreement $n^{\circ} 316796$.
} 
enjoyment of human rights. It is not possible to build a framework that respects human rights without considering the cultural identity of individuals and groups, especially if they are a minority in their respective policy fields”.

Following the lead of the Common Basic Principles for Immigrant Integration of the European Union (COM(2005)389 final) as well as those of the Council of Europe (Resolution 1618, State of democracy in Europe. Measures to improve the democratic participation of migrants, 2008) integration is understood, throughout the essays in this issue, as a dynamic two-way process which involves migrant and minority persons but also the members of the receiving society and its institutions. This conception of integration opposes other ideas which can be found in European countries' policies and political discourse and which see integration mainly as an individual responsibility. Although for a very long time this responsibility to integrate has been deemed to be performed mainly in the labour market, it is an increasingly noticeable landmark of current integration policies the fact that the immigrant's duty to integrate is displaced to the cultural realm: "fitting migrants" are not only those economically useful to our markets; they must show that they are capable of integrating culturally in our societies as well.

The (perceived) capacity to integrate, which plays a growing role in migrants getting access to the territory of receiving states, is often assessed on assumed ideas of the migrants' culture and of receiving societies' culture, as well as of the value and hazards attributed to cultural diversity itself.

Cultural diversity has played out in different directions in Europe. While it is proclaimed as the foundations of democratic pluralism and a requirement for cultural vitality and social and economic performance (Council of Europe, White Paper on Intercultural dialogue, 2008), when it comes to immigrant populations and integration policies cultural diversity has been long talked of in terms of hindrance or obstacle and has often become an explanation for conflicts between migrants and native population of the receiving states.

Different cultural elements, the membership to national, regional or ethnic communities, and kinship networks are also acknowledged to play an important role in facilitating newcomers' settlement and integration. Yet, whereas they ease the tasks of states' institutions by providing a bridge towards new immigrants, these same cultural elements and bounded communities are perceived as potential trouble: pull-factor for immigration from any given origin, hazards of enclosed minority enclaves, selfexclusion and parallel institutions run outside the reach of the state.

Finally, a third ambiguous theme in the topic of cultural diversity and immigration which is confronted in the essays in this issue is the question of change, spatial and time dimensions of dynamicity which accompany cultural cues in integration processes for transnational communities and for globalised cultural processes of hybridation. 
This special issue, therefore, aims at assessing how cultural elements are displayed in relation to integration by different migrant or minority communities. The issue opens with the contribution of Eduardo Ruiz Vieytez, who focuses on the main cultural traits that define minorities in the institutional language and that are relevant for integration policies. Among the several cultural traits that might be cohesive for groups and communities, Ruiz Vieytez examines those which have traditionally been considered in law and politics for defining minorities, that is, "cultural elements that provide the basis for building these identities that give rise to an asymmetric and politically relevant diversity". The author assesses the distinct roles attributed in this respect to language and religion and he identifies ethnicity as a "third space" of cultural diversity which is not as clearly conceptualised or codified. Both language and religion are important cues in the integration processes of migrant communities. Yet, the article shows the different challenges these two cultural traits pose in their relation to human rights and integration. The third type of minority considered in the article, ethnic minorities, is a more ambiguous category and much more subjected to the dynamicity, evolution and interaction which results from transnationalism and globalised migration movements.

This is the case of the Saharawi community in Spain, which María López Belloso analyses in the second article. The Saharawi community, as many of the other groups considered in this special issue, has the dual characteristic of being an immigrant community and a transnational community. Here, culture and its role in the integration of Saharawi communities in Spain must be read through the lens of transnationalism, of those processes through which migrant communities generate and maintain more or less constant relations and social activities which link societies of origin with destination societies. Following Thomas Faist's distinction of transnational spaces into family groups, transnational circuits and transnational communities, López Belloso highlights the latter for its clear cultural implications in terms of symbolic links such as religious membership, language, nationality or ethnicity, or - as it is the case with the Saharawi community in Spain - political commitment to a national cause. López Belloso's essay assesses precisely the impact of the temporal dimension and the dynamicity of transnational communities in the case of Saharawi exiles and migrants. In this case, the individuals' commitment to the national cause trumps over more traditional understandings of culture in forging the links that constitute the community, also in the light of a process of dilution and hybridation of traditional Saharawi cultural traits in the transnational spaces of the diaspora.

The third and fourth essays take up the issue of culture "construction" and "deconstruction" in the specific case of the Roma. Roma integration has been for some time now a key topic in European debates on integration. The essay by Tina Magazzini follows the development of one such European supported actions, the creation of the European Roma Institute (ERI). In the debates around the establishment of the ERI, several problems in the relationship between identity and recognition, economic exclusion and political representations are interwoven. The author analyses the criticisms and counter-criticisms to the ERI with Elizabeth Anderson's and Nancy Fraser's frameworks in the background: cultural promotion and social integration 
through culture are not as clear-cut policy action as it might appear. Magazzini considers issues raised under three accounts: cultural (the problem of reification), socioeconomic (the problem of displacement) and political (the problem of misframing) and gauges the political and economic potential that cultural identity holds in societies where exclusion and poverty are turned into cultural traits.

Kitti Baracsi also addresses issues related to Roma integration and culture, in the specific context of the school. Her essay resorts to engaged ethnography to make explicit the tensions inbuilt to the processes by which different educational actors produce the image of Roma students and related ideas about their culture and integration. This type of research allows a very specific understanding of the unique characteristics of the context in each school and how Roma identity or "Gypsyness" are created by comparison to surrounding environments and existing conflicts, both within Roma communities and with the non-Roma population. This "production of normality", Baracsi argues, is also key to explaining how Roma students are framed as a "separate problem" notwithstanding the problems they present at school might be the same identified for other (non-Roma) students. In this process the role attributed to (perceived) Roma culture and lifestyle by school actors, non-Roma students and families, NGOs and other stakeholders plays a central role in the "ethnizisation of marginality” and discriminatory practices.

Karolina Nikielska-Sekula explores the role of cultural heritage in the integration of young Norwegians of Turkish descent, in particular the role of cultural heritage in defining the boundaries of Turkish ethnicity for these younger generations. Her research shows the complexity of negotiating culture and belonging in avoiding the feeling of "being from nowhere". This is particularly exemplified by cultural practices brought to Norway by earlier generations which, under the conditions and influence of Norwegian society, have evolved differently than in Turkey and created unique cultural patterns. The author analyses intercultural practices from a triple standpoint: dual belonging, dual non-belonging, boundary making and crossing. Shared cultural heritage helps these communities to position themselves locally in Norway and, at the same time, for renegotiating traditional practices and values. The author shows this "third space" of Norwegian Turks (different from both Norwegian mainstream society and Turkey) as a reflective self-identity founded on a particular (and contextualized) appropriation of cultural practices and elements.

Self-identity and cultural integration constitute also the leading thread of the last contribution by Claudia Paraschivescu. She explores the complex emotions of Romanian expatriates in Paris and London who are considering going through the process of naturalisation and the way they consider British or French passports in relation to their social positioning in receiving societies. Notwithstanding Romanians being EU citizens exercising intra-EU freedom of movement, which is a fundamental pillar of the Union, these communities have been subjected to restrictions in relation to work-related migration and family reunification as well as to more or less explicit forms of social discrimination. The author compares Romanian communities in London and Paris and the differentiated stories about integration and belonging told by their quest or 
desire for a passport. Although there is a variety of reasons behind naturalisation, Paraschivescu concludes, Western citizenships provide Romanian expatriates with a sense of security, if not of belonging, and effective access to equal rights which the European Union has sadly failed to secure to everyone within the Union. 